\title{
PREPARATION AND CHARACTERIZATION OF SYNTHETIC CHITOSAN USING BIO-WASTE (SNAIL SHELL)
}

\author{
${ }^{1}$ OYEDEKO Kamilu F.K., ${ }^{2}$ AKINYANJU Adewale Sunday A., \\ ${ }^{1}$ AKINBOMI Julius, ${ }^{2}$ LASISI Mosunmola K., ${ }^{1}$ ADESINA Aramide A. \\ ${ }^{1}$ Department of Chemical Engineering, Lagos State University. \\ ${ }^{2}$ Department of Chemical Engineering and Petroleum, University of Lagos
}

Received: $4^{\text {th }}$ April 2019

Accepted: $9^{\text {th }}$ July 2019

Published: $17^{\text {th }}$ September 2019

https://doi.org/10.47545/etrj.2019.4.2.071

\begin{abstract}
In this paper chitosan was produced from chitin synthesis from inexpensive bio-waste (snail shell). This is a chemical process in which the chitin was produced through demineralization, deproteinization and decolorization while the chitosan obtained from chitin was by deacetylation. The physiochemical and functional properties such as nitrogen, moisture content, ash, degree of deacetylation, viscosity of the snail shell chitosan was considered. The product is characterized by Fourier transform infrared (FTIR) and scanning electron microscope (SEM). The degree of deacetylation (DD) is one of the main characterizing parameters of the chitosan. FTIR spectroscopy was used to calculate the degree of DD of chitosan. Chitosan with a high degree of deacetylation $(76.7 \%)$ was obtained by deacetylation with $50 \% \mathrm{NaOH}$ for $2 \mathrm{hrs}$ at $85^{\circ} \mathrm{C} . \mathrm{SEM}$ analysis shows the micro pores and microstructures of the sample. This is importance because the more the micro pores available in a sample, the better the adsorption capacity of that sample. The result of Energy Dispersive X-ray Spectroscopy (EDS) shows the elements Oxygen, Carbon, Magnesium, Calcium and phosphorus are present in the chitosan produced. The chitosan produced confirms the production of quality chitosan of low-cost adsorbent from the biowaste snail shell.
\end{abstract}

Keywords: Bio-waste, Chitosan, Deacetylation, Physiochemical properties, Snail shell

\section{INTRODUCTION}

One of the ways of reducing huge waste and accumulation of waste being generated is utilization of these wastes, (agro, bio, industrial and municipal). Researchers and industrialists continue to intensify efforts in reducing wastes by converting them to useful materials and chemicals. Snail shell is bio-waste that can be converted to a useful products chitosan and chitin. The most abundant natural biopolymer found in nature is cellulose, while chitin is second to it. Chitin is a crystalline polysaccharide with high molecular weight [1], [2], [3]. It is widely found in marine invertebrates, insects fungi, and yeast [4]. The principal variety source of chitin is available mostly in shell fish waste such as shrimps, crabs, and crawfish [1],[3][5]. It also exists naturally in a few species of fungi but not present in higher plants and higher animals. In terms of its structure, chitin is a homopolymer of $\beta$ - $(1 \rightarrow 4)$ linked $N$-acetyl-D-glucosamine. Chitin fibrils are embedded in a matrix of calcium carbonate and phosphate that also contains protein. The matrix is proteinaceous, high in protein contents where the protein is hardened by a tanning process,[6][7]. It was found that the shell of some crustacean consists of protein (30-40\%), calcium carbonate and calcium phosphate (30-50\%), and chitin (20-30\%) [8], [9]

Chitosan is a non-toxic, biodegradable polymer of high molecular weight, and is very much similar to cellulose, a plant fiber [2]. Chitosan is a fiber-like substance derived from chitin but chitosan possesses unique properties including the ability to form films, optical structural characteristics. Chitosan also possesses a positive ionic charge, which gives it an ability to chemically bind with negatively charged fats, lipids and bile acids [10]. Chitosan has three reactive functional groups, amine, primary and secondary hydroxyls Chitosan is a cationic semi-crystalline polysaccharide having a linear chain of 2-amino-2-deoxy-d-glucopyranose and 2-acetamido-2deoxy-d-glucopyranose repeating units linked by $\beta(1 \rightarrow 4)$ which can be obtained by deacetylation of chitin.[11]

It does offer potential for covalent and ionic modifications allowing the improvement of its mechanical and biological properties. 
The chemical structures of chitin and chitosan are similar. Chitin has linear chain of acetylglucos amine groups while removing enough acetyl groups $\left(\mathrm{CH}_{3}-\mathrm{CO}\right)$ from chitin gives chitosan, the molecule and the resultant product is found to be soluble in most diluted acids.

The actual difference between chitin and chitosan is the acetyl content of the polymer. The free amino group present in chitosan makes it the most useful derivative of chitin [9], [12].

However, the chitosan physicochemical characteristics affect its functional properties, which also differ due to crustacean species and preparation methods [9], [13], [14].

Chitosan is useful in wide applications (which depend on its physical, chemical, and biological properties) in various industries such as food biotechnology, pharmaceuticals. In addition, the chitosan is used in environment and agriculture such as water treatment, seed treatment and other applications [15], [16]. The chitosan has several useful features such as biocompatibility, biodegradability, non-toxicity, antibacterial property and largely used in biomedical and industrial fields as well as in industrial wastewater treatment [1], [17]. Chitosan derivative has gained wide attention as effective biosorbent because of the low cost and high contents of amino and hydroxyl functional groups which show significant adsorption potential for the removal of the various dyes contaminated [18].

Over the years, many researchers have developed and proposed several procedures for preparation of chitosan from different crustacean shell wastes. From which some of the basis of chemical processes for industrial production are formed and most of the reported processes were carried out at $100^{\circ} \mathrm{C}$ or higher temperature with autoclaving [19][20][21][22]. The production of chitin and chitosan, is through three-stage extraction, namely demineralization, deproteinization and deacetylation [23]. The traditional isolation of chitin from crustacean shell waste consists of three basic steps: demineralization (calcium carbonate and calcium phosphate separation), deproteinization (protein separation), and decolorization (removal of pigments). These three steps are the standard procedure for chitin production [2][24]. The subsequent conversion of chitin to chitosan (deacetylation) is generally achieved by treatment with concentrated sodium hydroxide solution $(40-50 \%)$ at $100^{\circ} \mathrm{C}$ or higher temperature to remove some or all of acetyl group from the chitin [9],[20],[25].

Therefore, the objectives of this work were to extract and characterize natural biopolymer chitosan from snail shell

\section{MATERIALS AND METHODS}

\subsection{MATERIALS}

All the chemical reagents used for this research work were of analytical grade and the reagents are: hydrochloric acid, Sodium hydroxide. Deionized water, Snail shells used for this experiment were obtained from dumpsite within Bariga and Epe fish market Lagos State Nigeria. The shells were scraped free of loose tissue, adhered dirty washed and with warm water to remove adhesion proteins with other impurities and dried in the oven at $105^{\circ} \mathrm{C}$ for I hour. The product was then crushed to small sizes and blended to powder in order to facilitate chemical extraction of quality chitosan. [26].

\subsection{PREPARATION OF CHITIN AND CHITOSAN}

There are four basics stages involved in production of chitosan. The stages are: deproteination, demineralization, depigmentation or decolorization and deacetylation.

\subsubsection{Preparation of Chitin}

The first stage in Chitosan production is Demineralization stage. The methods employed for the production of chitin from snail shell was as described by [26]. 500g of the sieved sample was weighed and put into a beaker. $2500 \mathrm{ml}$ of $3.25 \mathrm{M}$ of $\mathrm{HCl}$ solution was added $(1: 5 \mathrm{w} / \mathrm{v})$. The mixture was stirred using a griffin shaker at $30^{\circ} \mathrm{C}$, for 2 hours to avoid effervescence and to remove carbonate and phosphate content. The resulting solution was washed with distilled water and filtered with Whatman filter paper. The residue was scraped into petri dish and dried in an oven at $105^{\circ} \mathrm{C}$ for 2 hours. In the deproteinization process, the demineralized chitin was soaked in $870 \mathrm{ml}$ of $2.39 \mathrm{M}$ of sodium hydroxide $(\mathrm{NaOH})$ solution $(\mathbf{1 : 1 5} \mathbf{w} / \mathbf{v})$. The mixture was stirred and boiled in a water bath at $70^{\circ} \mathrm{C}$ for 2 hours. The resulting solution was filtered with Whatman filter paper and washed with distilled water and decolorized with acetone and more water until the $\mathrm{pH}$ of the filtrate is neutral. After washing the mixture was filtered and the residue put in an oven $105^{\circ} \mathrm{C}$ for $2 \mathrm{hrs}$ to dry. The resultant product was chitin 


\subsubsection{Preparation of Chitosan}

The obtained chitin was soaked in $750 \mathrm{~mL}$ of $50 \mathrm{wt} / \mathrm{wt} \% \mathrm{NaOH}$, and heated at $85^{\circ} \mathrm{Cfor} 2$ hours, $30 \mathrm{mins}$ in a water bath and cooled for $30 \mathrm{~min}$ at room temperature. The mixture was placed on a magnetic stirrer at $30^{\circ} \mathrm{C}$ for 4 hours. The mixture was washed and the $\mathrm{pH}$ of the filtrate was constantly checked until it is neutral. Thereafter, the mixture was filtered using Whatman filter paper to retain the solid matter. The chitosan thus produced was dried in an oven at $105^{\circ} \mathrm{C}$ for 2 hours. This process of converting chitin to Chitosan by removal of acetyl groups is generally achieved by treatment with concentrated sodium hydroxide solution is known as deacetylation [26], [27]. Sample of chitosan prepared is shown in plate 1.

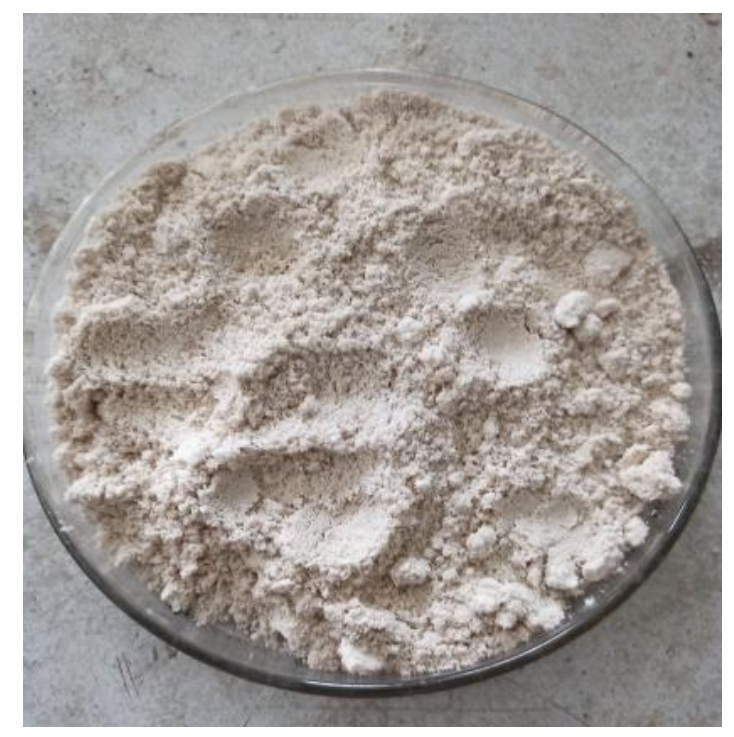

Plate 1: Sample of Chitosan produced from snail shell

Determination of Ash Content: $5 \mathrm{~g}$ of sample was weighed inside a crucible and placed inside a muffle furnace with temperature set at $525^{\circ} \mathrm{C}$ and was heated for 6 hours to burn off all the nutrients and fiber present. The crucible was then removed and allowed to cool indesiccators. Ash content in percentage was calculated as [9], [28]

$$
\text { Percent Ash }=\frac{\text { Ash weight }}{\text { sample weight }} \times 100
$$

Determination of Moisture Content: $1 \mathrm{~g}$ of the sample was weighed into a pre-weighed beaker and placed in an oven for about three (3) hours at a temperature of $100^{\circ} \mathrm{C}$ to a constant weight. The difference in weight indicates the amount of water contained in the same [29]

Percentage Moisture Content $=\frac{\text { Weight of original sample-Weight of dry sample }}{\text { Weight of original sample }} \times 100$

Determination of Crude Fiber: $1 \mathrm{~g}$ of the sample was put in a pre-weighed beaker. $50 \mathrm{ml}$ of $1.25 \%$ sulphuric acid was added and made up to $100 \mathrm{ml}$ with distilled water and stirred. The mixture was heated with continuous stirring for thirty (30) minutes and allowed to cool and settle. It was then decanted and was washed three(3) times with de-ionized water to make the mixture acid free. $50 \mathrm{ml}$ of $1.25 \% \mathrm{NaOH}$ was added and the mixture was heated for thirty (30) minutes with continuous stirring. It was cooled and settled. It was decanted and washed three (3) with de-ionized water. The mixture was filtered and the content was transferred into a crucible. The content was then dried in an oven at a temperature of $100^{\circ} \mathrm{C}$ for two hours until a constant weight was obtained; it was the allowed to cool and re-weighed.

Percentage crude fiber $=\frac{\text { Weight of residue }- \text { Weight of ash }}{\text { Weight of sample }} \times 100$

Determination of Nitrogen and Crude Protein: $1 \mathrm{~g}$ of the sample was weighed using a filter paper then transferred to Kjeldahl's tube, $25 \mathrm{ml}$ of concentrated $\mathrm{H}_{2} \mathrm{SO}_{4}$ was added; a dark brown solution was observed. $3.0 \mathrm{~g}$ of digestion mixed catalyst $\left(\mathrm{CuSO}_{4}+\mathrm{NaSO}_{4}\right)$ was added. The mixture in the digestion tube was transferred to the digestion apparatus, the heater was regulated below the boiling point of the acid until frothing ceased. The mixture boiled vigorously as temperature was increased until a clear solution was obtained. The digest was allowed to cool and 
then transferred into $100 \mathrm{~cm}^{3}$ volumetric flask. It was then diluted with distilled water to make up to $100 \mathrm{~cm}^{3}$. 10 $\mathrm{ml}$ aliquot of the digest was introduced into the distillation jacket connected to the main water source. As the water in the distiller flask boiled, $20 \mathrm{ml}$ of $40 \% \mathrm{NaOH}$ was added to the digest in the distillation jacket. $50 \mathrm{ml}$ of $4 \%$ boric acid was measured into $250 \mathrm{ml}$ conical flask and 4 drops of methyl red indicator was added. The conical flask containing the mixture was placed onto the distillation apparatus with the outlet tube inserted into the conical flask and $\mathrm{NH}_{3}$ was collected through the condenser. The distillation continued until $25 \mathrm{ml}$ of the distillate was trapped into the boric solution and colour changed from red to yellow. The distillate was the titrated with $0.02 \mathrm{M}$ $\mathrm{HCl}$. Percentage nitrogen and crude protein was calculated.

Percentage Protein Content $=$ Nitrogen content $\times$ Conversion factor

Conversion factor of Nitrogen to Protein $=6.25$

Percentage Nitrogen $=\frac{(\text { Titer Value }- \text { Blank }) \times \text { Conc. of Acid } \times \text { Molar Mass of Nitrogen } \times 100}{\text { Weight of sample } \times 1000}$

\subsection{CHARACTERIZATION OF PRODUCED CHITOSAN}

Determination of degree of deacetylation: The degree of deacetylation (DD) of chitosan is an important parameter for characterizing chitosan as it affects the solubility, chemical reactivity and biodegradability of chitosan. Chitosan is characterized by either the degree of acetylation (DA), which corresponds to the Nacetylamine groups, or the degree of deacetylation DDA [30].The degree of acetylation (DA) is different from the degree of deacetylation (DD). They are opposite one another. A chitosan of $80 \%$ DD has $20 \%$ of acetyl groups and $80 \%$ of amine groups on its chains.DD of chitosan influences the physicochemical properties of chitosan significantly such as solubility, overall charge, reactivity and biological properties Also, mechanical properties such as elongation, breaking, and tensile strength.[27][31]. The degree of deacetylation (DD) determined by FTIR (infrared spectroscopic) analysis because they are widely available, low-cost and required little time for analysis [9][26][32]. The Degree of deacetylation refers to the removal of acetyl group from the chain [18]. This is determined by FTIR spectroscopy have been performed in the transmission mode, with chitosan contained in potassium bromide (KBr) tablets. DD may range from $30 \%$ to $95 \%$ [16], depending on the available source and procedure. $100 \%$ DD is very scarcely obtained, with commercial chitosan with various DD in the range of $75-85 \%$. IR technique was used to determine the degree of deacetylation, DD, of chitosan, according to the methods described by [26], [27]. The degree of deacetylation (DD) of the refined chitosan from snail shells was calculated using equation given as:

$$
D D \%=100-\left[\left(\frac{A_{1655}}{A_{3450}}\right) * \frac{100}{1.33}\right]
$$

Where, $\mathrm{A}_{1655}$ and $\mathrm{A}_{3450}$ are the values of absorbance at the wavelengths 1655 and $3450 \mathrm{~cm}^{-1}$ respectively.

The absorbance values were calculated using equation $\mathrm{A}=2-\log _{10}(\% \mathrm{~T})$

Where $\mathrm{T}=$ Transmittance.

Scanning Electron Microscope (SEM): Joel Scanning Electron Microscope (model JSM 7600F) (SEM) machine was used for surface texture and morphological characteristics of the adsorbents.

Fourier-Transform Infrared Analysis (Ft-Ir): Fourier Transform infrared spectrometer was used to identify and characterize unknown materials. A sample of $20 \mathrm{mg}$ of chitosan powder was blended with $120 \mathrm{mg}$ of potassium bromide $(\mathrm{kBr})$ (spectroscopy grade) with a mortar and pestle for approximately 10-15 minutes. The mixture was compacted to form a disk. The disk was conditioned in a desiccator placed in an oven at $80^{\circ} \mathrm{C}$ for 16 hrs before analysis. This was done to prevent any interference with any existing water vapour or carbon dioxide molecules. The resulting sample was then analyzed with FTIR spectrometer.

\section{RESULTS AND DISCUSSION}

Table 1 shows proximate analysis of chitosan from snail shell respectively.

FTIR was performed to confirm the formation of chitosan. The peaks appearing in the FTIR spectrum were assigned to various functional groups according to their respective wave numbers as reported in the literature. Various absorption bands within the $4000-350 \mathrm{~cm}^{-1}$ range were extracted from the FTIR spectra of chitosan, 
prepared from snail shell. The adsorption bands for the prepared chitosan and significant peaks are presented in Table 2.

A characteristic band at $3445.00 \mathrm{~cm}^{-1}$ could be assigned to the stretching vibrations of $-\mathrm{NH}_{2}$, and $-\mathrm{OH}$, associated with primary amines and with pyranose ring respectively. The peak at $2927.76 \mathrm{~cm}^{-1}$ was due to the presence of $\left(\mathrm{CH}_{2}\right)$ in $\mathrm{CH}_{2} \mathrm{OH}$ group. The observed peak at $1631.73 \mathrm{~cm}^{-1}$ was due to the presence of the $(\mathrm{C}=\mathrm{O})$ in $\mathrm{NHCOCH}_{3}$ group. The observed peak at $1056.00 \mathrm{~cm}^{-1}$ was assigned to $(\mathrm{C}-\mathrm{O})$ in secondary $\mathrm{OH}$ group. The observed band at $685.36 \mathrm{~cm}^{-1}$ was attributed to $\mathrm{NH}$ out-of-plane bending [34].

Table 1: Proximate Analysis of Chitin and Chitosan

\begin{tabular}{|l|l|l|}
\hline Parameter & Chitin & chitosan \\
\hline Moisture Content (\%) & 4.10 & 2.47 \\
\hline Ash (\%) & 0.86 & 1.02 \\
\hline Protein (\%) & 5.31 & 3.09 \\
\hline Crude Fibre(\%) & 3.12 & 6.41 \\
\hline
\end{tabular}

Fourier Transform Infrared (FTIR) Characterization of Chitosan: FTIR was done to confirm the formation of chitosan from snail shell. The peaks appearing in the FTIR spectrum were assigned to various functional groups according to their respective wavelengths as reported in the literature. Various absorption bands within the 4000$350 \mathrm{~cm}^{1}$ range were recorded in the FTIR spectra of chitosan, prepared from snail shell.

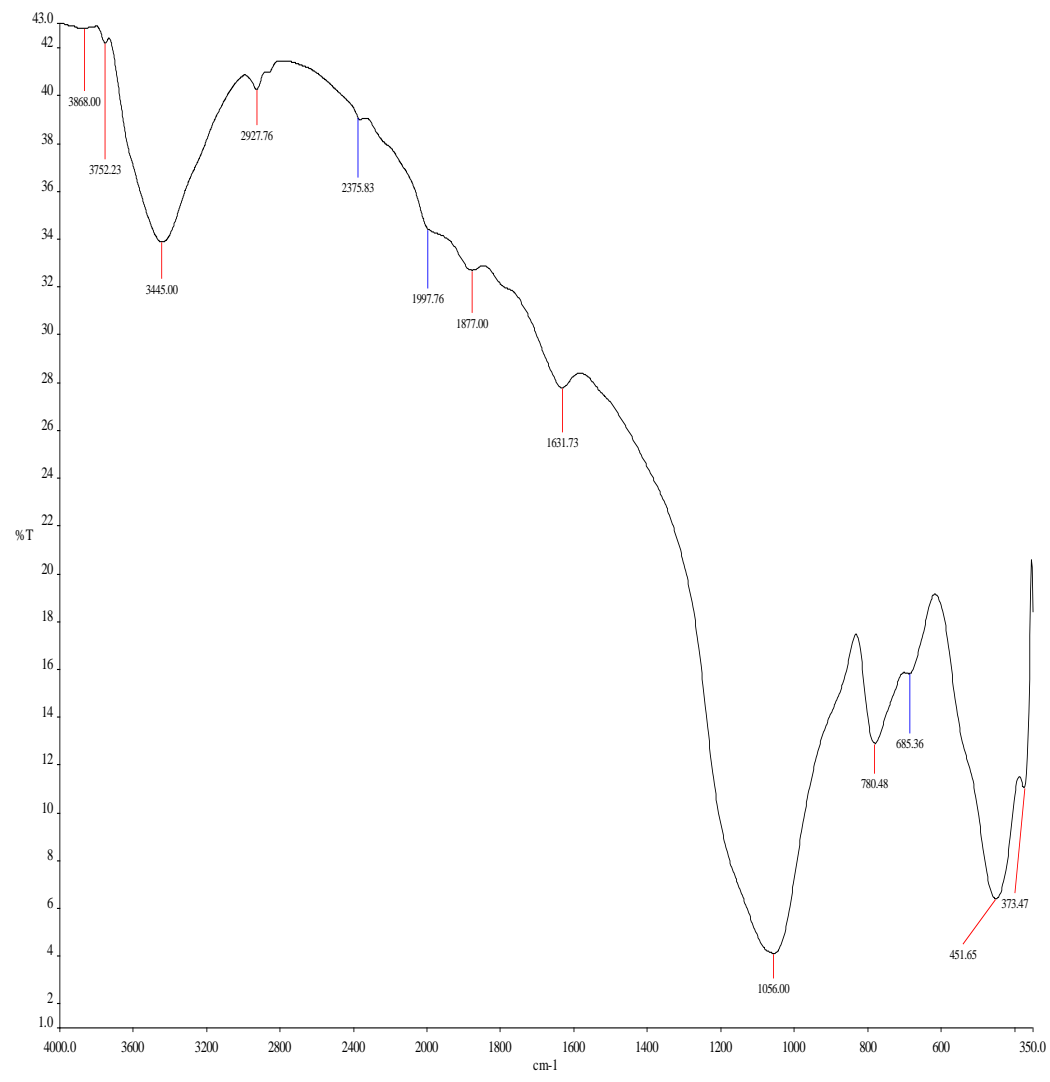

Figure 1: FTIR spectra of chitosan

Degree of Deacetylation: From the FTIR analysis of chitosan, the \% transmittance of the wavelength 1320 and $1420 \mathrm{~cm}^{-1}$ was obtained as $21.5 \%$ and $25.1 \%$ respectively. The degree of deacetylation (DD) of the chitosan sample was obtained to be $76.7 \%$. 
Table 2 Comparison of FTIR spectrum with standard spectra from Sigma Aldrich

\begin{tabular}{|l|l|l|l|}
\hline Wave number & \multicolumn{2}{|c|}{ Functional groups } \\
\hline $\begin{array}{l}\text { Experimental } \\
\mathrm{cm}^{-1}\end{array}$ & $\begin{array}{l}\text { Sigma Aldrich } \\
\text { Standard } \mathrm{cm}^{-1}\end{array}$ & $\%$ error & \\
\hline 3445.00 & 3422 & \pm 0.67 & $\begin{array}{l}\text { v(NH2) associated with primary amines and } \\
(\mathrm{OH}) \text { associated with pyranose ring }\end{array}$ \\
\hline 2927.76 & 2923 & \pm 0.163 & $\mathrm{v}(\mathrm{CH} 2)$ in CH2OH group \\
\hline 1631.73 & 1655 & \pm 1.41 & $\mathrm{v}(\mathrm{C}=\mathrm{O})$ in NHCOCH3 group (amide I band) \\
\hline 1562.01 & 1554 & \pm 0.51 & $\mathrm{v}(\mathrm{NH} 2)$ in NHCOCH3 group (amide II band) \\
\hline 1056.00 & 1073 & \pm 1.58 & (C) $-\mathrm{O})$ in secondary OH group \\
\hline 685.36 & 662 & \pm 3.53 & $\delta(\mathrm{NH})$ out of plane \\
\hline
\end{tabular}

SEM Analysis: Scanning Electron Microscope is an instrument used to determine the surface morphology of materials. It also helps to obtain information about the surface topography and composition of material. SEM can as well be used to discover and evaluate surface fractures and also helps to examine surface contamination. The SEM images in Fig 2 and Fig 3. However, with a magnification of 15000, as shown in Fig 4 rough surface, irregular block and crystalline cluster was observed. SEM analysis shows the micro pores and microstructures of the sample. This is importance because the more the micro pores available in a sample, the better the adsorption capacity of that sample.

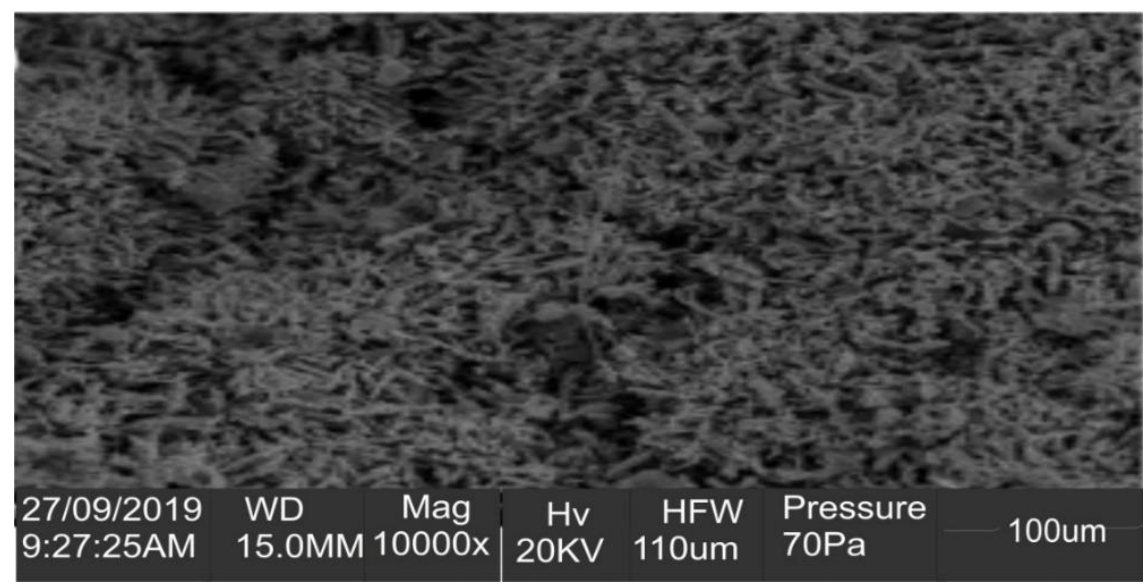

Figure 2. SEM image of Chitosan X10000

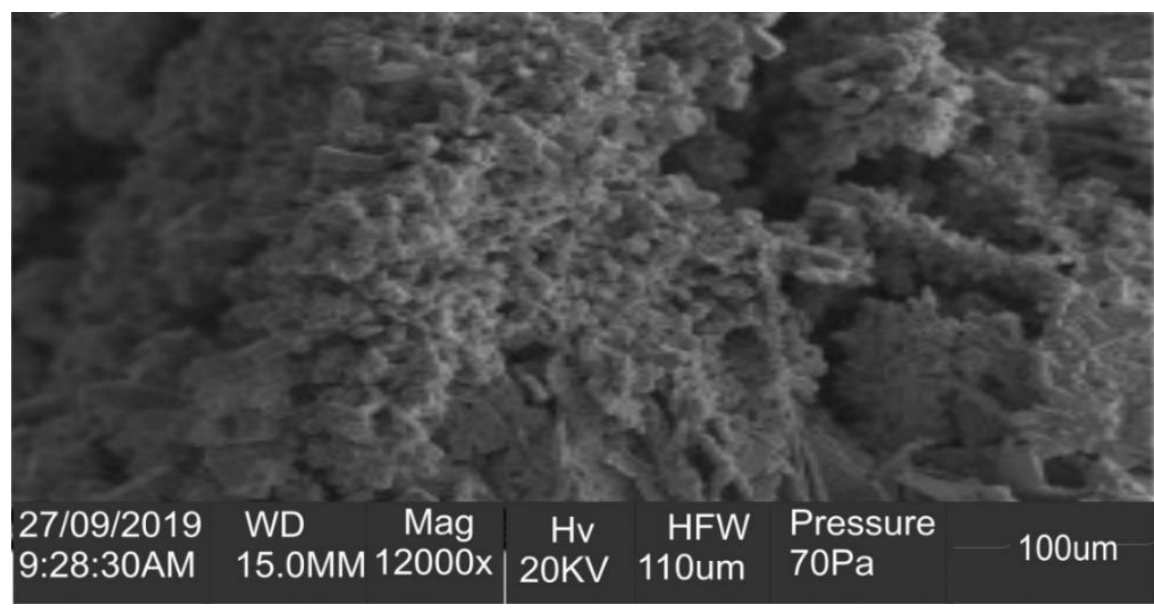

Figure 3 SEM image of Chitosan X12000 


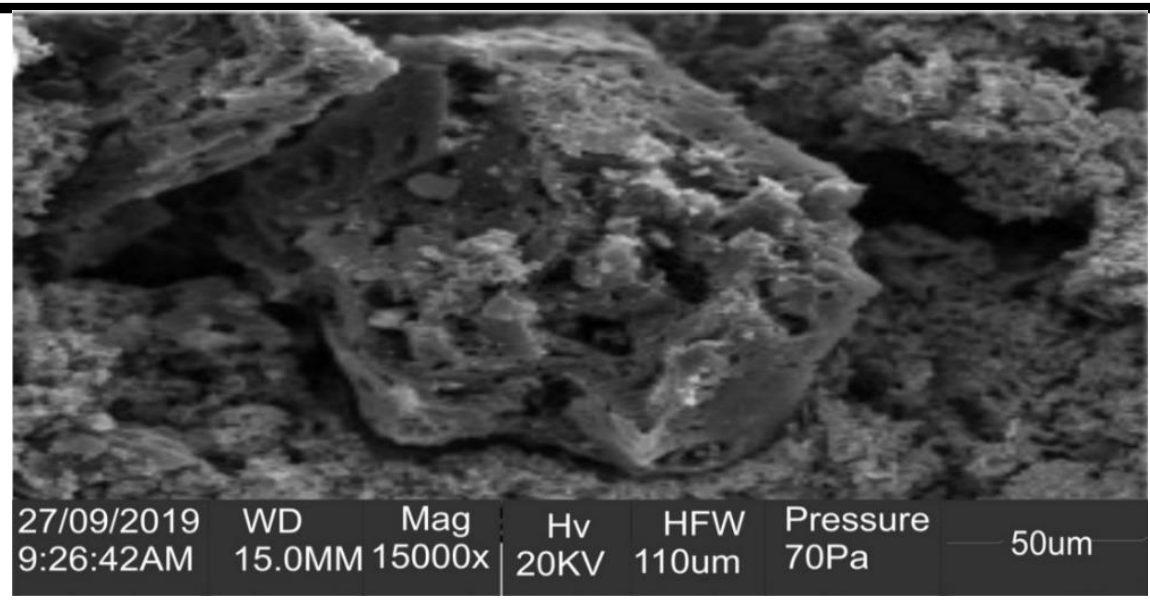

Figure 4 SEM image of Chitosan X15000

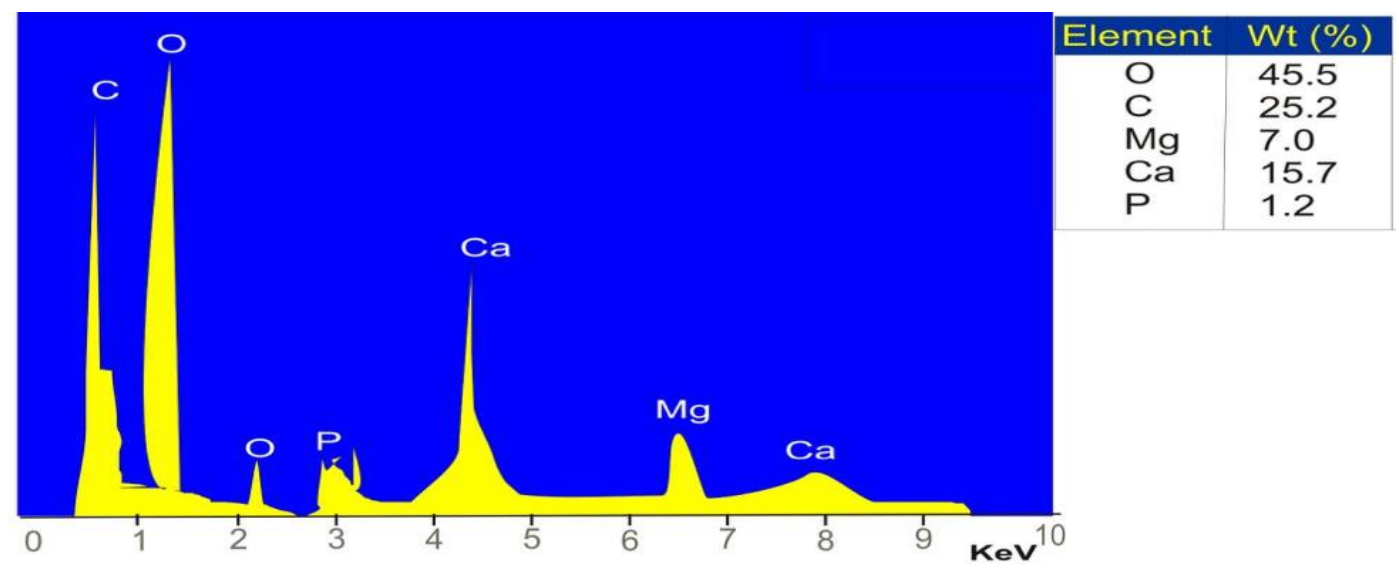

Figure 5 EDS spectra of Chitosan.

EDS Analysis of Chitosan: The result of Energy Dispersive X- ray Spectroscopy (EDS) shows the elements present in the chitosan produced. Oxygen, Carbon, Magnesium, Calcium and phosphorus are presence in the chitosan sample as shown in Fig 5 above. Oxygen has the highest peak in the EDS spectrum followed by Carbon and Calcium. The EDS compositional analysis results obtained on spectrum of the extracted chitosan from snail shells shows a weight percent of Oxygen (45.5wt \%), Carbon (25.2 wt \%), Magnesium (7.0wt\%), Calcium (15.7 wt \%) and Phosphorus (1.2 wt \%).

\section{CONCLUSION}

The results obtained from this research indicates that chitosan from locally low-cost raw materials (snail shell) biowaste through chemical methods, deprotenization, demineralization and deacetylation. Functional and physiochemical properties were evaluated by many methods FTIR, SEM, and EDS analysis. FTIR is relatively fast and does not require dissolution of chitosan sample in an aqueous solvent. The quality and properties of chitosan vary widely with crusean species. The quality and physicochemical properties of chitosan vary widely with the kind of raw material used to produce chitosan and also on the methods of preparation. There was agreement between the characteristic band of standard chitosan and the chitosan produced from snail shell confirms the production of quality chitosan from the biowaste snail shell used in this study at high temperature is in agreement with other authors. It can therefore be concluded that chitosan produced from snail shells is an effective, efficient and low-cost adsorbent. 


\section{REFERENCES}

[1] Kumari S, Rath PK (2014) Extraction and characterization of chitinand chitosan from (Labeo Rohit) fish scales. Procedia MaterSci 6:482-489

[2] No H. K. and Meyers S. P. (1989). Crawfish Chitosan as aCoagulant in Recovery of Organic Compounds fromSeafood Processing Streams. J. Agric. Food Chem.37(3): 580-583.

[3] Rinaudo M (2006) Chitin and chitosan: properties and applications.Prog Polym Sci 31(7):603-632

[4] Austin P. R., Brine C. J., Castle J. E. and Zikakis J. P. (1981).Chitin: New facets of research. Science. 212:749-753

[5] Allan C. R. and Hadwiger L. A. (1979). The fungicidal effectof chitosan on fungi of varying cell wall composition. Exp. Mycol. 3: 285-287.

[6] Muzzarelli R. A. A. (1976). Chitin; Pergamom press, Oxford.

[7] Muzzarelli R. A. A. and Muzzarelli C. (2005). Chitosan chemistry: Relevance to the biomedical sciences. AdvPolym. Sci. 186: 151-209

[8] Knorr D. (1984). Use of chitinous polymers in food- A challengefor food research and development. FoodTechno l. 38(1): 85-97.

[9] Nessa, F., Masum, Shah Md., Asaduzzaman. M., Roy, S.K.,Hossain. M.M and Jahan M.S., (2010) A Process for the Preparation of Chitin and Chitosan from Prawn Shell Waste Bangladesh J. Sci. Ind. Res. 45(4), 323-330, 2010

[10] Sandford P. A. (1992). High purity chitosan and alginate:Preparation, analysis, and applications. Front.Carbohydr. Res. 2: 250-269.

[11] Younes I, Ghorbel-Bellaaj O, Chaabouni M et al (2014) Use of a fractional factorial design to study the effects of experimental factorson the chitin Deacetylation. Int J Biol Macromol 70:385 -390

[12] No H. K. and Meyers S. P. (1992). Utilization of CrawfishProcessing Wastes as Carotenoids, Chitin, and ChitosanSouces. J. Korean Soc. Food Nutr. 21:319-326.

[13] Cho Y. I., No H. K. and Meyers S. P. (1998).Physicochemical Characteristics and FunctionalProperties of various Commercial Chitin and ChitosanProducts. J. Agric. Food Chem. 46(9): 3839-3843.

[14] No H. K., Lee K. S. and Meyers S. P. (2000). CorrelationBetween Physicochemical Characteristics and BindingCapacities of Chitosan Products. J. Food Sci.65(7):1134-1137.

[15] Jana, S., Saha, A., Kumar Nayak, A., Kumar Sen. K and Basu,S.K., (2013) "Aceclofenac-loaded chitosantamarind seed polysaccharide interpenetrating polymeric network microparticles", Colloids and Surfaces B: Biointerfaces. Vol. 105, pp.303-309, (2013).

[16] Mukhopadhyay, P., Sarkar, K., Soam.,S and Kundu,P.P, (2013) "Formulation of pH-responsive carboxy methyl chitosan and alginate beads for the oral delivery of insulin", Journal of Applied Polymer Science, Vol.129, No. (2), pp.835-845, (2013).

[17] Robinson, T., McMullan, G., Marchant. R and Nigam, P., (2001) "Remediation of dyes in textile effluent: a critical review on current treatment technologies with a proposed alternative". Bioresour. Technol.Vol.77, pp. 247-255, (2001).

[18] Popuri, S.R., Vijaya, Y., Boddu, V.M and Abburi, K. (2009)“Adsorptive removal of copper and nickel ions from water using chitosan coated PVC beads", Bioresource Technology, Vol. 100, No. 1, pp. 194-199, (2009). 
[19] Domard A. and Rinadudo M. (1983). Preparation and characterizationof fully deacetylated chitosan. $J$. Biol.Macromol. 5: 49-52.

[20] Galed G., Diaz E. and Heras A. (2008). Conditions of Ndeacetylationon chitosan production from alpha chitin.Nat. Prod. Commun. 3(4): 543-50.

[21] Horton D. and Lineback D. R. (1965). N-deacetylation, chitosanfrom chitin. In: Whistler RL, Wolfson ML, Eds.Methods in Carbohydrate Chemistry. New York:Academic Press. pp.403.

[22] Prashanth R. and Tharanathan R. (2007). Chitin/chitosan:modifications and their unlimited application potentialanoverview. Trends Food Sci. Tech. 18: 117-31.

[23] Mohammed MH, Williams PA, Tverezovskaya O (2013) Extractionof chitin from prawn shells and conversion to low molecularmass chitosan. Food Hydrocoll 31(2):166-171

[24] No H. K., Meyers S. P. and Lee K. S. (1989). Isolation andCharacterization of Chitin from Crawfish Shell Waste.J. Agric. Food Chem. 37(3):575-579.

[25] No H. K. and Meyers S. P. (1995). Preparation andCharacterization of Chitin and Chitosan-A Review. J.Aquatic Food Prod. Technol.. 4(2):27-52.

[26] Moosa, A., Ridha, A., \& Kadhim, N. (2016). Use of Biocomposite Adsorbents for the Removal of Methylene Blue Dye from Aqueous Solution. American Journal of Materials Science,6(5), 135-146.

[27] Duarte ML, Ferreira MC, Marvao MR, Rocha J. (2002) An optimized method to determine the degree of acetylation of chitin and chitosan by FTIR spectroscopy. International Journal of Biological Macromolecules. 2002;31(1-3):1-8

[28] AOAC (2005) Official method of Analysis. 18th Edition, Association of Officiating Analytical Chemists, Washington DC, Method 935.14 and 992.24.

[29] AOAC (2000) Official Methods of Analysis. 17th Edition, The Association of Official Analytical Chemists, Gaithersburg, MD, USA. Methods 925.10, 65.17, 974.24, 992.16.

[30] Biskup,R., Jarosińska,C.D., Rokita, B., Ulański, P and Rosiak,J.M (2012) "Determination of degree of deacetylation of chitosan - comparision of methods ",

[31] Chatelet O, Damour A, Domard A.(2001) Influence of the degree of acetylation onsome biological properties of chitosanfilms. Biomaterials. 2001;22:261-268

[32] De Alvarenga, E.S. "Characterization and Properties of Chitosan",(2011).

[33] Martino AD, Sittinger M, Risbud MV (2005). Chitosan: A versatile biopolymer for orthopaedic tissueengineering. Biomaterials 26:5983- 5990.

[34] Sneha P, Aiswarya J, Changam S.S, \& Sanjay MC (2014) Extraction and purification of Chitosan from chitin isolated from sea praw. Asian Journal Pharmaceutical andClinical Research 7:201-204 